\title{
Design of Multiband Compact H-Shaped Microstrip patch antenna for Wireless application
}

\author{
Poonam Shukla ${ }^{1}$, S.P. Gangwar ${ }^{2}$ \\ Kamla Nehru Institute of Technology, Sultanpur U.P ${ }^{1,2}$
}

\begin{abstract}
Microstrip Patch Antenna (MPA) provides low profile and low volume, so it is use in a now a days in communication device. A new high gain, multiband $\mathrm{H}$-shape slot loaded microstrip patch antenna is presented in this paper. By introducing wideband $\mathrm{H}$-shape slot antenna multiband are merged together which gives the maximum bandwidth of $22.1 \%$ and the gain of $6.7522 \mathrm{dBi}$. The antenna is printed on a dielectric substrate, backed by a metal board, and directly fed from a $50 \Omega$ coaxial cable. Using HFSS software package according to the set size, the antenna is simulated. The composite effect of integrating these techniques and by introducing the novel slotted patch offers a low profile, wide bandwidth, high gain and compact antenna element. The computer simulation results show that the antenna can realize wide band characters. In this paper, a design of H-Shape microstrip patch antenna is given for multiband operation. This type of smaller antenna has application in mobile phone for Wi-Max, Bluetooth, C-band, Sband and also for other wireless applications.
\end{abstract}

Keywords: Microstrip Patch Antenna, Multiband H-shape slot, Coaxial Probe and HFSS.

\section{INTRODUCTION}

The speedy development of wireless communication has increased the demand for miccrostrip patch antenna with high gain and multiband operating frequencies. The use of multiband microstrip patch antennas in portable device like mobile phone, laptop, gaming etc., some microstrip patch antenna has various advantage such as low profile, conformal, light weight, integrate-ability and compatibility with standard manufacturing process. However, the general microstrip patch antennas have some disadvantage such as narrow bandwidth, low gain and interference etc. Enhancement of the performance to cover the demanding bandwidth is necessary. There are numerous and well known methods to increase the bandwidth of antennas including increase of the substrate thickness, the use of a low dielectric substrate, the use of various impedance matching and feeding technique, and the use of multiple resonators. The antenna can both transmitting and receiving the information so it is the essential part of the microwave communication. It is a device that is made to efficiently radiate and receive the radiated electromagnetic waves. Antenna is a transducer which convert the voltage and current on a transmission line into an electromagnetic field in a space, consisting of an electric and magnetic field travelling right angles at each other .The most commonly employed microstrip patch antenna is a rectangular patch.

In this paper a printed multiband antenna fed by a coaxial probe is used. The antenna is simulated using High Frequency Structure Simulator technology. The result shows the impedance bandwidth has achieved a good match.

\section{ANTENNA DESIGN}

The dielectric constant FR-4 epoxy (4.4) $1.6 \mathrm{~mm}$ of the substrate is closely related to the microstrip antenna. Low dielectric of the substrate produces larger bandwidth, the high dielectric constant of the substrate results in smaller size of antenna. A trade-off relationship exists between antenna size and bandwidth.

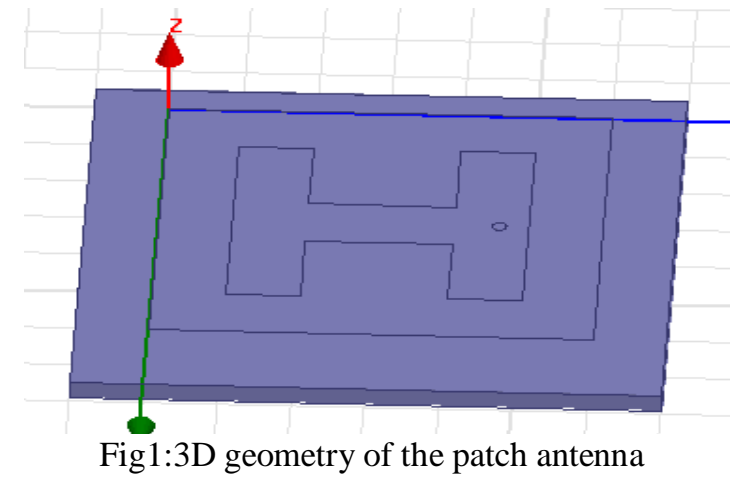




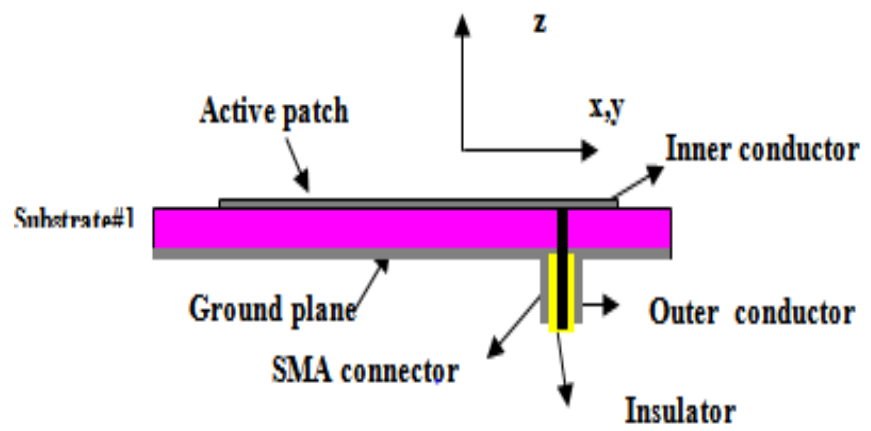

Fig2 : Side View of Designed Antenna

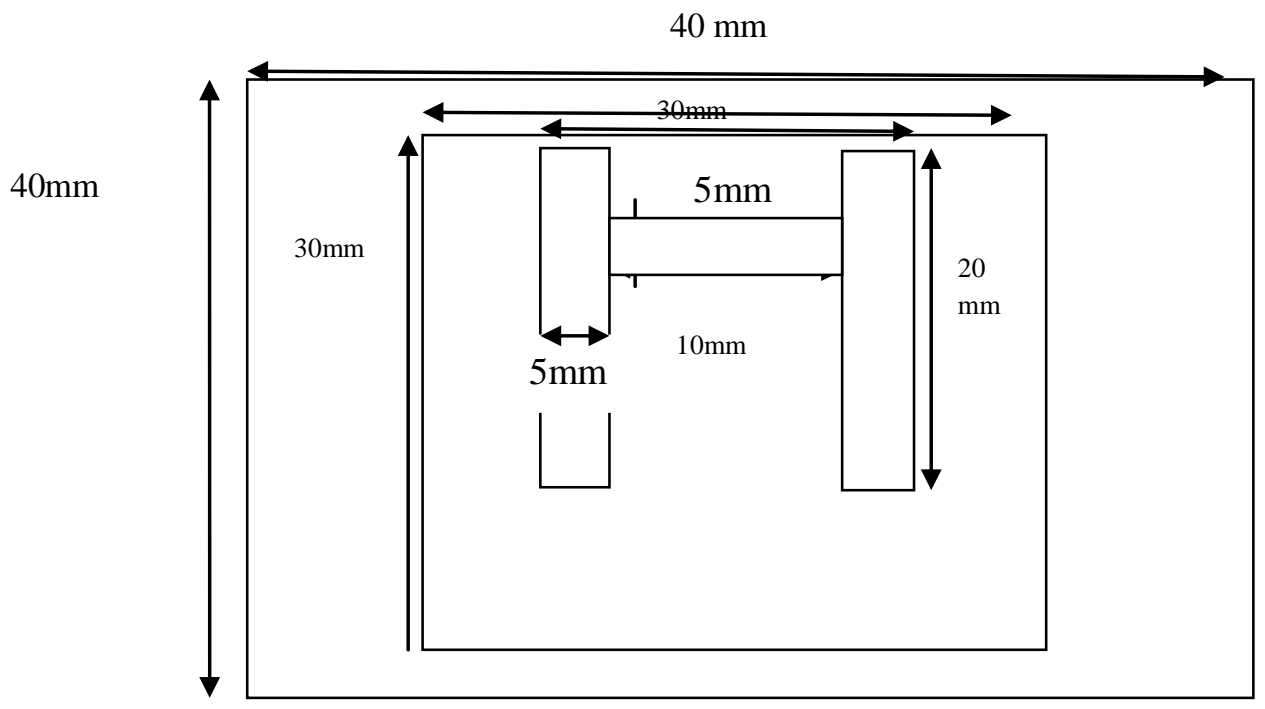

Fig3: dimensions of patch antenna

\section{MICROSTRIP PATCH}

The following drawing shows a patch antenna in its basic form, a microstrip antenna (Printed Antenna) generally fabricated using microstrip technique. It is most commonly used in microwave industries. An individual microstrip antenna consists of a patch of metal foil of different shapes and sizes on surface of a PCB ( printed circuit board), with a metal foil ground plane on the other side of the board. The patches are in two dimensional arrays. Depending on application we may design multiple patch on same PCB. The feeding is connected in two manners either microstrip line feeding or co-axial feeding. Feeding is always connected to patch.

The electric field is always zero at the centre of patch, it is maximum at one side and minimum at another side of the patch. The electric field doesn't stop abruptly at the boundary of patch.

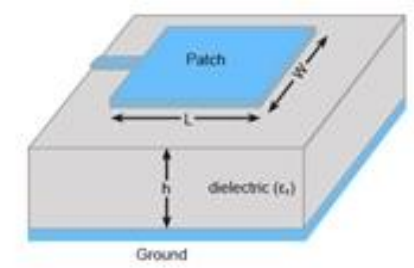

Fig4: Basic Structure of microstrip patch antenna

\section{RESULTS AND DISCUSSIONS}

The proposed antenna is designed by using Ansoft HFSS13 software .The given results simulated by HFSS software. Figure 5 shows the return loss versus frequency plot of the proposed antenna. From the plot it is seen that the antenna resonates at $4.58 \mathrm{GHz}$ of frequency. The experimental bandwidth is calculated by the formula. 
Bandwidth $(\%)=\frac{\mathrm{F} 2-\mathrm{F} 1}{\mathrm{Fc}} \times 100$

Here, F2 and F1 are the upper and lower cut-off frequencies of the resonted band provides return loss of -10dB or less than of $-10 \mathrm{~dB}$, where $\mathrm{Fc}$ is centre frequency between $\mathrm{F} 2$ and $\mathrm{F} 1$.

Figure 6 Shows the 3D radiation pattern of proposed antenna, which having Omni-directional radiation pattern.

Figure 7 shows the Gain Vs frequency curve, from the graph we can conclude that the maximum gain of the proposed antenna is $6.7522 \mathrm{dBi}$.

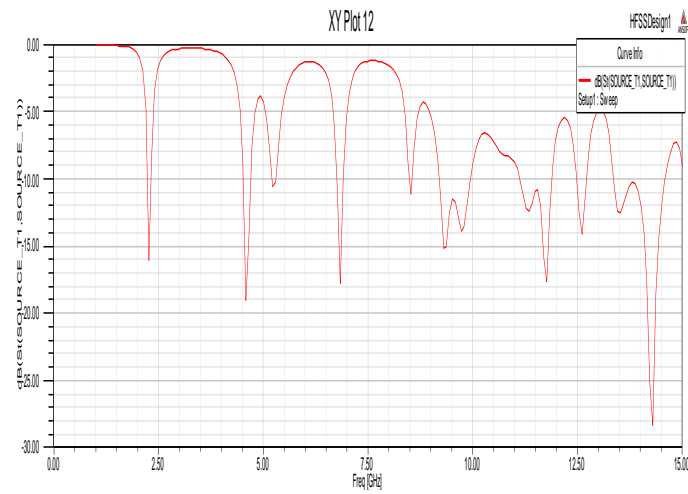

Fig 5: Return loss of proposed antenna

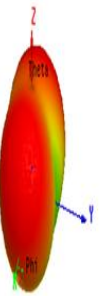

Fig 6: 3D radiation pattern of Antenna

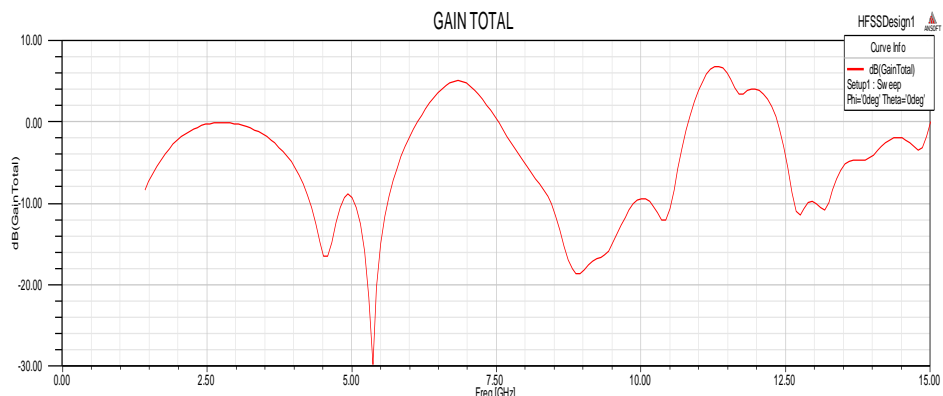

Fig7: Gain of The Proposed Antenna

\section{CONCLUSION}

Simulation results of a wideband microstrip patch antenna having $4.58 \mathrm{GHz}$ frequency has been proposed in this design. Better antenna performance and impedance matching can be realized by adjusting the position of probe and patch dimensions. It is concluded from the results of the proposed antenna that the designed antenna has satisfactory performance and hence is best suitable for WLAN application.

\section{REFERENCES}

[1] Fan Yang, Xue- Xia Zhang, "Wide band E shaped patch antennas for wireless communications" IEEE Transactions on Antenna and Propogation, Vol. 49, pp- 1094-1099, july 2001.

[2] B-K Ang and B-K Chung, "A wideband E shaped microstrip patch antenna for 5-6 GHz wireless communications", Progress in Electroomagnetics Research, Vol. 75, pp. 397-407,2007.

[3] M. T. Islam, M. N. Shakib and N. Misran, "Broadband E-H shaped microstrip patch antenna for wireless systems," Progress In Electromagnetics Research, PIER 98, 163-173,2009.

[4] K. Kumar and N. Gunasekaran, "A novel wideband slotted mm wave microstrip patch antenna," Proc. IEEE Vol. 987-1. pp. 10-14, 2011.

[5] Swaraj Panusa, "Quad band H slot microstrip patch antenna for WiMAX application", International Journal of computer application, Vol. 103, pp-14-16, October 2014.

[6] Shailander Singh Khangarot, Gajendra Sujediya, Abhishek Kumar, "Design and fabrication of E slot microstrip patch antenna for WLAN application", International Journal of advanced Research in complex \& communication engineering, Vol. 4, pp-149-154, June 2015.

[7] Carver K R "Practical analytical techniques for the microstrip antenna, Proc Workshop Printed Circuit Antenna Technology" (New Mexico State Univ, Las Cruces, USA), 1979.

[8] Chen W S, Hung C \& Wong K L, “A novel microstrip-line-fed printed semicircular slotantenna for broadband operation”, Microw Opt Technol Lett (USA), 26 (2000) 237.

[9] Binod k. kanaujia," Reactive loaded annular ring microstrip patch antenna”. Indian journal of radio and space physics, vol. 35, pp, 122-128, 2006.

[10] Prof Jaikaram Singh, "Design and simulation of microstrip E-shaped patch antenna for improved bandwidth \& directive gain", IJETT, Vol. 9,pp-446-450, Mar 2001.

[11] Fan Yang, Xue- Xia Zhang,“Wide band E shaped patch antennas for wireless communications” IEEE Transactions on Antenna and Propogation, Vol. 49, pp- 1094-1099, july 2001. 